\title{
Use of Fractals Channels to Improve a Proton Exchange Membrane Fuel Cell Performance
}

\author{
Pablo Martin Belchor ${ }^{1,2}$, Paloma Barbieri ${ }^{2}$, Gabriel Benetti ${ }^{2}$, Evandro Mathias ${ }^{2}$, Mayra Klein ${ }^{2}$, João Bottin ${ }^{2}$, \\ Deyse Suman Carpenter ${ }^{3}$ and Maria Madalena Camargo Forte ${ }^{1}$ \\ 1. Department of Materials, School of Engineering, UFRGS (Federal University of Rio Grande doSul)/PPG3M (Postgraduate \\ Program in Mining, Metallurgy and Materials), Porto Alegre 91501-970, Brazil \\ 2. Exact and Technological Sciences, UNOESC (University of Oeste de Santa Catarina), Campus II, Joaçaba 89600-000, Brazil \\ 3. Department of Materials, the FURB (Foundation Regional University of Blumenau), Campus II, Blumenau 89030-000, Brazil
}

Received: April 27, 2015 / Accepted: June 11, 2015 / Published: August 31, 2015.

\begin{abstract}
One of the most important and effective hardware elements for improvement of efficiency and power density of proton exchange membrane fuel cells is the flow field plate. The design and the pattern of the flow field plate have a considerable effect on the effectiveness of mass transport as well as on the electrochemical reactions inside the cell. The configuration of the flow field plate aims at ensuring a low pressure-drop over all channels in the stack. In this work, a FPFFP (fractal parallel flow field plate), with bio-inspired configuration by insertion of fractals in a classic PFFP (parallel flow field plate), is proposed, increasing the flow area of the hydrogen at anode side without increasing the section's area of the flow field plate. By simulating was observed that, the use of channels in fractal shape can increase the hydrogen flow area without occuring pressure loss in the cell. The fluid dynamic behavior in the FPFFP at smaller scales was replicated in the same plate, with better advantage of the active area of the electrode. Increasing the hydrogen flow area without causing pressure loss could be a good tactic to increase the power density of fuel cells, and consequently improving the cell performance.
\end{abstract}

Key words: Fuel cells, flow field design, fractals, power, simulation.

\section{Introduction}

The main driving force for the fuel cell research, development and commercialization is due the global concern with the pollutant emissions, especially from the transport and industries sectors [1,2]. Fuel cells, in particular the PEMFC (proton exchange membrane fuel cell) are lately extensively being studied due to its potential as alternate source for energy generation for mobile applications, mainly in the transport sector [3-5]. Fuel cells have technological unique attributes such as high-energy efficiency, low or no emissions of pollutants and absence of moving parts [3].

A hydrogen fuel cell is an electrochemical device that converts chemical energy stored by hydrogen fuel

Corresponding author: Pablo Martin Belchor, professor, research fields: modelling and simulation, and fuel cell system. E-mail: rafrstv@hotmail.com. into electricity. The heart of a PEM (proton exchange membrane) fuel cell is the MEA (membrane electrode assembly), which includes the membrane, the catalyst layers and GDLs (gas diffusion layers). The catalytic reaction of hydrogen with oxygen from air, used as oxidant, produces more electricity per fuel mass than any other non-nuclear method of power production [4]. The most important hardware components and effective for improvement of efficiency and power density in a PEMFC are the bipolar plates. The surfaces of the plates contain a flow field, which is a set of channels to direct the hydrogen to the anode, and the oxygen to the cathode on the MEA. The bipolar plates are used to assemble individual PEM fuel cells into a fuel cell stack, collect the electronic current and remove generated water [5]. The design of the flow field plate and its pattern have great effect on the effectiveness of 
mass transport as well as electrochemical reactions inside the cell. The channels' design (dimension, shape, pattern and configuration) is very important for better bipolar plate. One of the goals of the flow field plate configuration is to ensure a low pressure drop over all the channels in all the stack cells [6].

Types of channel configurations with fractal branching patterns occurs in nature, found in crystals formation, landscapes shaped by water drainage, lightning bolts, in certain plants and in the human body. Fig. 1 [7] shows some examples of fractal anatomical systems. Fractals are not just stunning visual effects, but inspiration source to model more complex patterns [8]. More generally, building something is typically flat, round or follows other shapes of very simple geometry. By contrast, shapes found in nature as ones in the mountains, clouds, broken stones and trees are highly complex [9].

In this work, a FPFFP (fractal parallel flow field plate), with bio-inspired configuration in fractals, and a classical PFFP (parallel flow field plate), the most popular plate, were comparatively modeled and evaluated by computer simulation.

\section{Objectives}

The aim of this work is to propose a plate with a bio-inspired flow field configuration to improve the flow area of the hydrogen at anode side of the MEA, with no pressure loss in the channels of the plate.

\section{Methodology}

\subsection{Designing the FPFFP}

An exploded view of a fuel cell stack in Fig. 2 shows one side bipolar plate with flow field used as pattern, facing the gas diffusion layer, used in both side of MEA. The classic and fractal parallel flow field were designed using SolidWorks software.

Fig. 3 shows SolidWorks images of the modeled structures, the new FPFFP and classic PFFP, for using CFD (computational fluid dynamics) to study the dynamic behavior of continuous fluid. The structures

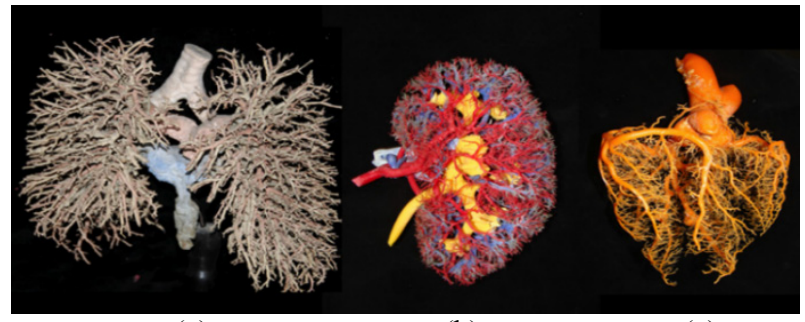

(a)

(b)

(c)

Fig. 1 Examples of "tree-like" fractal anatomic systems (from left to right: (a) bronchial tree; (b) renal vascular and urinary systems; (c) heart coronary system).

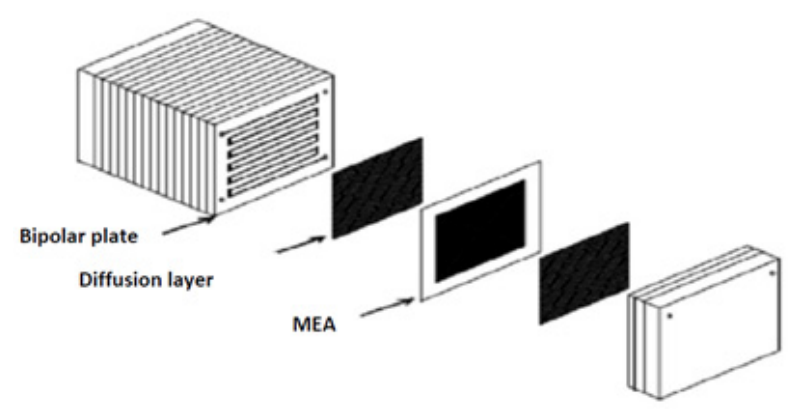

Fig. 2 Exploded view of a PEMFC stack.

of the channels were characterized by repeating a self-similarity at different size scales inspired in a biological branching pattern [10]. To insert various fractals channels in the classic PFFP was created connections between every channels of the flow field. Each new channel attached successively of smaller size maintaining the same similarity increases considerably the active surface area of the flow field.

\subsection{Simulation Tests Using CFD}

The tests were performed using SolidWorks software 2013 with flow simulation tool, and a computer Alienware Aurora Desktop BRH3171 equipped with Intel ${ }^{\circledR}$ Core $^{\mathrm{TM}}$ i7-960 (3.2 GHz, $8 \mathrm{MB}$ L3 cache; 24 GB DDR3 1,333 MHz memory/6 × 4 GB) and an liquid cooler high-performance (Alienware ${ }^{\circledR}$ ). The tests performed for each CFD using the plates classical PFFP and the fractals have ranged from a few minutes to over $3 \mathrm{~h}$, respectively.

In the simulation tests, the temperature of both flow field plates was controlled at $100^{\circ} \mathrm{C}$. At the cell anode side, in channel inlet, the hydrogen flow at $25{ }^{\circ} \mathrm{C}$ was of $1 \mathrm{~L} / \mathrm{min}$, and in the channel outlet, the hydrogen 


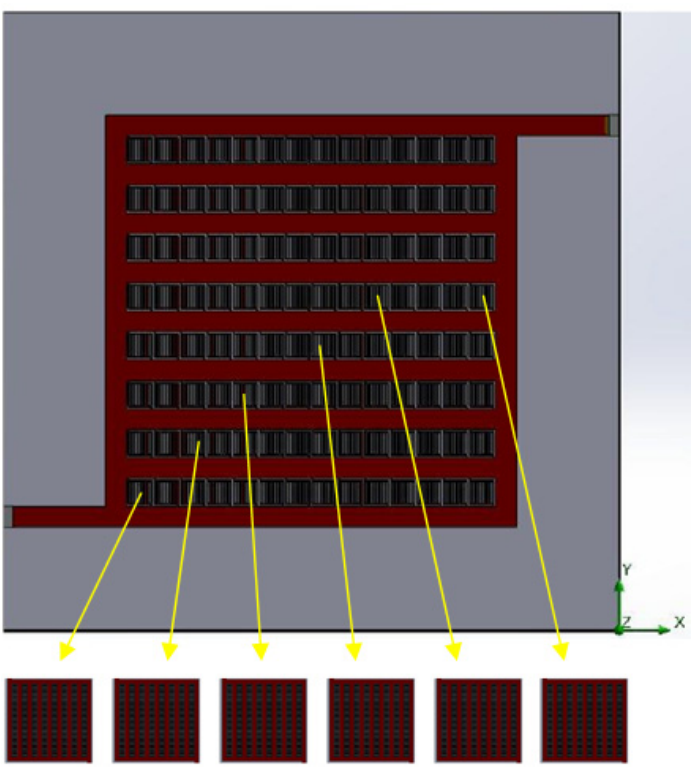

(a)

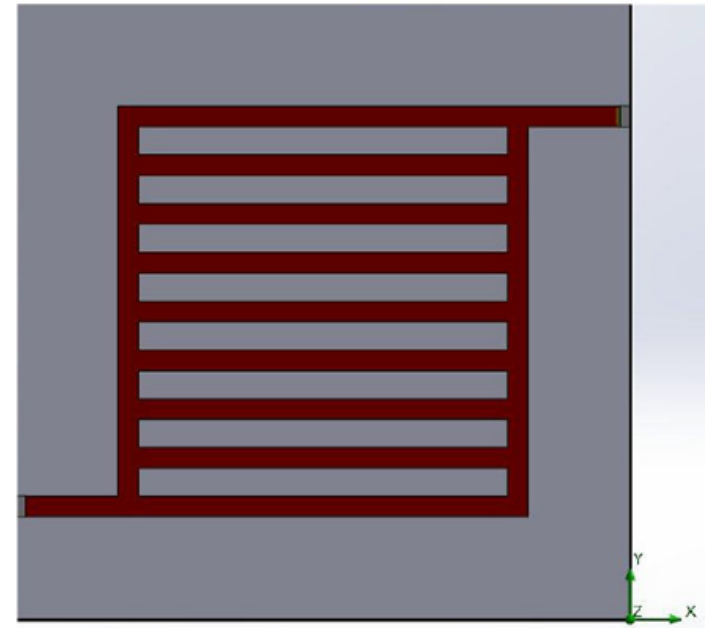

(b)

Fig. 3 SolidWorks images of (a) FPFFP; (b) PFFP.

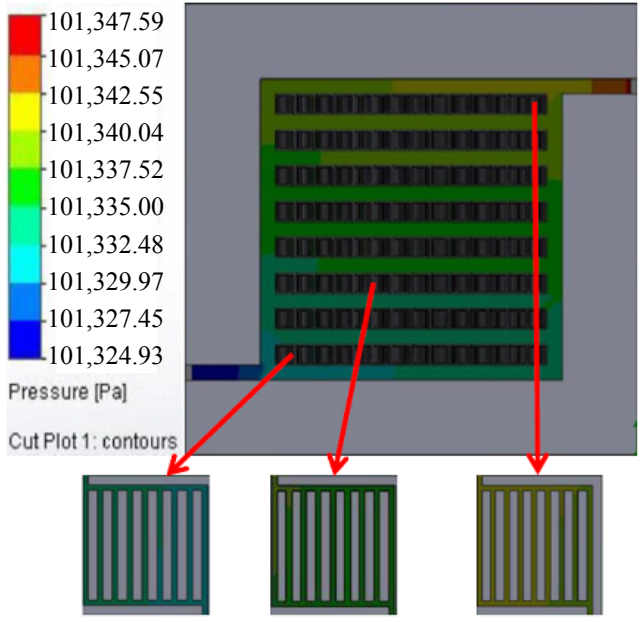

(a)

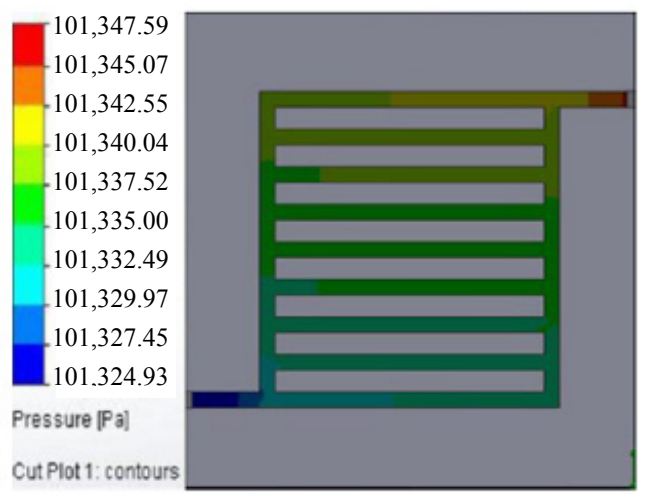

(b)

Fig. 4 Figured images of the CFD simulation with the (a) FPFFP and (b) PFFP.

pressure was equal environmental-pressure.

\section{Results and Discussion}

Figured images of the CFD simulation using FPFFP and the PFFP are shown in Fig. 4. The fluid dynamic test results had shown pressure variation in the hydrogen flow similar for both FPFFP and PFFP. The hydrogen pressure decreased as the reagent approaches the flow field outlet. In the fractals channels of the FPFFP, the fluid dynamic behavior of the hydrogen has been repeated at smaller scales in the same plate. In both flow field plates, the minimum pressure was of $101,324.93 \mathrm{~Pa}$, and the maximum pressure of 101,347.59 $\mathrm{Pa}$, occurring pressure-loss of 22.66 Pa. Although the pressure loss has been equal in both kind of flow field channel, the hydrogen flow occurred in a larger volume in the channels with fractals.

Tables 1 and 2 show the parameters minimum and maximum values, respectively, for the FPFFP and PFFP flow field channels. 
Table 1 Min/max parameters of the FPFFP CFD.

\begin{tabular}{lll}
\hline & Minimum & Maximum \\
\hline Pressure $(\mathrm{Pa})$ & $101,324.93$ & $101,347.59$ \\
Temperature $(\mathrm{K})$ & 298.15 & 373.15 \\
Density $\left(\mathrm{kg} / \mathrm{m}^{3}\right)$ & 0.07 & 0.08 \\
Velocity $(\mathrm{m} / \mathrm{s})$ & 0 & 10.739 \\
Temperature (fluid) $(\mathrm{K})$ & 298.15 & 373.15 \\
Mach number & 0 & $7.32 \mathrm{e}-003$ \\
Vorticity $(1 / \mathrm{s})$ & 0 & $51,040.651$ \\
Shear stress $(\mathrm{Pa})$ & 0 & 1.62 \\
Heat transfer coefficient & $7.284 \mathrm{e}-014$ & $2,367.446$ \\
$\left(\mathrm{~W} /\left(\mathrm{m}^{2} \cdot \mathrm{K}\right)\right)$ & -56.488 & $188,677.647$ \\
Surface heat flux $\left(\mathrm{W} / \mathrm{m}^{2}\right)$ & 0 & $146,972.979$ \\
Heat flux $\left(\mathrm{W} / \mathrm{m}^{2}\right)$ & 0
\end{tabular}

Table 2 Min/max parameters of the PFFP CFD.

\begin{tabular}{lll}
\hline Name & Minimum & Maximum \\
\hline Pressure $(\mathrm{Pa})$ & $101,324.93$ & $101,347.59$ \\
Temperature $(\mathrm{K})$ & 298.15 & 373.15 \\
Density $\left(\mathrm{kg} / \mathrm{m}^{3}\right)$ & 0.07 & 0.08 \\
Velocity $(\mathrm{m} / \mathrm{s})$ & 0 & 10.739 \\
Temperature (fluid) $(\mathrm{K})$ & 298.15 & 373.15 \\
Mach number & 0 & $7.32 \mathrm{e}-003$ \\
Vorticity $(1 / \mathrm{s})$ & 2.198 & $51,038.952$ \\
Shear stress $(\mathrm{Pa})$ & $1.83 \mathrm{e}-005$ & 1.62 \\
Heat transfer coefficient & $7.405 \mathrm{e}-013$ & $2,367.448$ \\
$\left(\mathrm{~W} /\left(\mathrm{m}^{2} \cdot \mathrm{K}\right)\right)$ & -0.234 & $188,678.372$ \\
Surface heat flux $\left(\mathrm{W} / \mathrm{m}^{2}\right)$ & 0 & $146,974.586$ \\
Heat flux $\left(\mathrm{W} / \mathrm{m}^{2}\right)$ & 0 & \\
\hline
\end{tabular}

\section{Conclusions}

The results showed that, in the anode of a PEMFC equipped with PFFP, fractals could increase the anode hydrogen flow area without increase the pressure loss and repeat the PFFP fluid dynamic behavior at smaller scales in the same plate. As a result, the MEA active area was bigger, improving the current density and consequently the fuel cell power density.

\section{Acknowledgments}

The Agencies CAPES (Coordenação de Aperfeiçoamento de Pessoal de Nível Superior) and
CNPq (Conselho Nacional de Desenvolvimento Científico e Tecnológico) are gratefully acknowledged. Pablo Martin Belchor thanks to the University UNOESC (University of Oeste de Santa Catarina) and UFRGS (Federal University of Rio Grande do Sul), and the companies Werjen Equipamentos, Future (Science and Technology) and Baterias Pioneiro for their financial support.

\section{References}

[1] Pierre, J. S., and Wilkinson, D. P. 2001. "Efficient and Cleaner Power Sorce." AlChe Journal 47 (7): 1482-6.

[2] Trimm, D. L., and Önsan, Z. I. 2001. "On-Board Fuel Conversion for Hydrogen Fuel Cell Driven Vehicles." Catalysis Reviews-Science and Engineering 43 (1-2): 31-84.

[3] Falcão, D. S., Gomes, P. J., Oliveira, V. B., Pinho, C., and Pinto, A. M. F. R. 2011. "1D and 3D Numerical Simulations in PEM Fuel Cells." International Journal of Hydrogen Energy 36 (19): 12486-98.

[4] Tseng, C. J., Tsai, B. T., Liu, Z. S., Cheng, T. C., and Chang, W. C. 2012. "A PEM Fuel Cell with Metal Foam as Flow Distributor." Energy Conversion and Management 62 (October): 14-21.

[5] Roshandel, R., Arbabi, F., and Karimi, M. G. 2012. "Simulation of an Innovative Flow-Field Design Based on a Bio Inspired Pattern for PEM Fuel Cells." Renewable Energy 41 (May): 86-95.

[6] Wang, J., and Wang, H. 2012. "Discrete Approach for Flow Field Design of Parallel Channel Configurations in Fuel Cells." International Journal of Hydrogen Energy 37 (14): 10881-97.

[7] Mandelbrot, B. 1983. The Fractal Geometry of Nature. New York: W. H. Freeman and Company, 113.

[8] Stewart, I. 2010. The Colours of Infinity. New York: Springer, 2-23.

[9] Mandelbrot, B. 2010. The Colours of Infinity. New York: Springer, 38-57.

[10] Arvay, A., French, J., Wang, J. C., Peng, X. H., and Kannan, A. M. 2013. "Nature Inspired Flow Field Designs for Proton Exchange Membrane Fuel Cell." International Journal of Hydrogen Energy 38 (9): 3717-26. 